\title{
Study on Cavitation Behavior of Pipe String in Gas Storage Well under Gas-Liquid Environment
}

\author{
Hang Yan ${ }^{1}$, Yifei Yan ${ }^{2, *}$, Xiangzhen Yan ${ }^{1}$ \\ ${ }^{1}$ College of Pipeline and Civil Engineering, China University of Petroleum, Qingdao 266580; \\ ${ }^{2}$ College of Mechanical and Electronic engineering, China University of Petroleum, Qingdao 266580 \\ *E-mail: 20180056@upc.edu.cn
}

doi: $10.20964 / 2021.03 .71$

Received: 16 October 2020 / Accepted: 7 January 2021 / Published: 31 January 2021

In the long-term and continuous operation process of UGS injection-production well, the outer casing joint of the oil string is prone to failure. This causes gas to enter into the annular space between the casing and string forming the gas-liquid two-phase, leading to the issue of cavitation of the string. Therefore, herein, the string cavitation caused by the gas leakage in UGS gas well during the injection and production process is analyzed through electrochemical measurements and image characterization. The results show that the pipe string had no corrosion characteristics during the long time of injection and production owing to the action of corrosion inhibitor and passivation film of $13 \mathrm{Cr}$. During the $24 \mathrm{~h}$ experiment, when the leakage pressure reached $5 \mathrm{MPa}$, the pipe string was mainly layered corrosion. When the pressure increased to $10 \mathrm{MPa}$, the formation and rupture of gas bubbles on the metal surface led to the destruction of two protective films, and clear cavitation pits appeared on the metal surface. Greater the pressure, more prominent was the cavitation effect.

Keywords: Cavitation behavior; UGS gas well; Electrochemical reaction; Gas-liquid two-phase environment

\section{$\underline{\text { FULL TEXT }}$}

(C) 2021 The Authors. Published by ESG (www.electrochemsci.org). This article is an open access article distributed under the terms and conditions of the Creative Commons Attribution license (http://creativecommons.org/licenses/by/4.0/). 